OPEN ACCESS

Edited by:

Wei Zhao,

Shandong University, China

Reviewed by:

Karel Allegaert,

University Hospitals Leuven, Belgium

Jiao Zheng,

Fudan University, China

*Correspondence:

O. Della Pasqua

o.dellapasqua@ucl.ac.uk

Specialty section:

This article was submitted to Obstetric and Pediatric Pharmacology,

a section of the journal

Frontiers in Pharmacology

Received: 31 October 2020 Accepted: 04 January 2021

Published: 08 March 2021

Citation:

D'Agate S, Musuamba FT, Jacqz-Aigrain $E$ and Della Pasqua O (2021) Simplified Dosing Regimens for

Gentamicin in Neonatal Sepsis.

Front. Pharmacol. 12:624662.

doi: 10.3389/fphar.2021.624662

\section{Simplified Dosing Regimens for Gentamicin in Neonatal Sepsis}

\author{
S. D'Agate ${ }^{1}$, F. Tshinanu Musuamba ${ }^{1}$, E. Jacqz-Aigrain ${ }^{2}$ and O. Della Pasqua ${ }^{1 *}$ \\ ${ }^{1}$ Clinical Pharmacology and Therapeutics Group, University College London, London, United Kingdom, ${ }^{2}$ Department of \\ Paediatric Pharmacology and Pharmacogenetics, Centre Hospitalier Universitaire, Hôpital Robert Debré, Paris, France
}

Background: The effectiveness of antibiotics for the treatment of severe bacterial infections in newborns in resource-limited settings has been determined by empirical evidence. However, such an approach does not warrant optimal exposure to antibiotic agents, which are known to show different disposition characteristics in this population. Here we evaluate the rationale for a simplified regimen of gentamicin taking into account the effect of body size and organ maturation on pharmacokinetics. The analysis is supported by efficacy data from a series of clinical trials in this population.

Methods: A previously published pharmacokinetic model was used to simulate gentamicin concentration vs. time profiles in a virtual cohort of neonates. Model predictive performance was assessed by supplementary external validation procedures using therapeutic drug monitoring data collected in neonates and young infants with or without sepsis. Subsequently, clinical trial simulations were performed to characterize the exposure to intra-muscular gentamicin after a q.d. regimen. The selection of a simplified regimen was based on peak and trough drug levels during the course of treatment.

Results: In contrast to current World Health Organization guidelines, which recommend gentamicin doses between 5 and $7.5 \mathrm{mg} / \mathrm{kg}$, our analysis shows that gentamicin can be used as a fixed dose regimen according to three weight-bands: $10 \mathrm{mg}$ for patients with body weight $<2.5 \mathrm{~kg}, 16 \mathrm{mg}$ for patients with body weight between 2.5 and $4 \mathrm{~kg}$, and $30 \mathrm{mg}$ for those with body weight $>4 \mathrm{~kg}$.

Conclusion: The choice of the dose of an antibiotic must be supported by a strong scientific rationale, taking into account the differences in drug disposition in the target patient population. Our analysis reveals that a simplified regimen is feasible and could be used in resource-limited settings for the treatment of sepsis in neonates and young infants with sepsis aged $0-59$ days.

Keywords: gentamicin, neonatal sepsis, pharmacokinetics, modeling and simulation, dosing optimization, bacterial infection, resource-limited and remote setting 


\section{INTRODUCTION}

Bacterial infections persist as a global health problem (UNICEF, 2018). Children mortality remains exceptionally high during the first month of life, with more than $99 \%$ of neonatal deaths occurring in developing countries. Moreover, a quarter of these deaths are attributed to neonatal sepsis (Liu et al., 2012; Chan et al., 2013; Lawn et al., 2014). The recommended initial empirical therapy for a neonate with suspected bacterial sepsis and/or meningitis includes ampicillin and an aminoglycoside (Zaidi et al., 2011; Polin et al., 2012; World Health Organization, 2015; Seale et al., 2015). This combination expands the antimicrobial spectrum and can be prescribed at a considerably low cost (Lee et al., 2014). However, despite the availability of clinical guidelines and recommendations for the treatment of serious bacterial infections in resource-limited settings, where the recommended inpatient treatment may not be feasible, challenges still exist in the effective delivery of lifesaving drugs to this vulnerable population (Lassi et al., 2010; Esamai et al., 2013; African Neonatal Sepsis Trial et al., 2015; Simen-Kapeu et al., 2015). In addition to accessibility, acceptability or affordability issues, this is also due to the complexity of the recommended dosing regimens, which have been introduced into clinical practice in a rather empirical manner. Such an approach does not warrant optimal exposure of newborns to antibiotic agents, which show a different disposition profile in this population (Cella et al., 2010a; Medellin-Garibay et al., 2015; Samardzic et al., 2016).

In fact, a few historical antibiotic efficacy trials were performed in neonates $>20$ years ago and these have been conducted without careful evaluation of the implications that differences in drug disposition represent for the dose rationale (Evans et al., 1986; Buring et al., 1988; Wiese, 1988; Fisk, 1993). By contrast, a vast body of evidence is currently available that allows one to assess the role of age and disease-related changes in drug disposition and overall differences in the pharmacokinetic properties of antibiotics (Manolis and Pons, 2009; Pandolfini et al., 2013; Roberts et al., 2014; Stockmann et al., 2014; Pineda and Watt, 2015). Here we assess the feasibility of a simplified regimen of gentamicin taking into account the effect of body size and organ maturation on pharmacokinetics. Using quantitative clinical pharmacology methods, and more specifically clinical trial simulations, we characterize the impact of covariate factors on the disposition of gentamicin in preterm and term infants aged 0-59 days. The aim of this analysis was to evaluate the performance of it is possible to evaluate current World Health Organisation (WHO) guidelines, which recommend gentamicin doses between 5 and $7.5 \mathrm{mg} / \mathrm{kg}$ and identify a simplified regimen for the use of intramuscular gentamicin in resource-limited settings.

Making use of clinical trial simulations, it is possible to evaluate clinically relevant scenarios including the effect of intrinsic (e.g., disease) and extrinsic (e.g., co-medication) factors known to alter the pharmacokinetic properties of a drug (Anderson, 2010; Bellanti and Della Pasqua, 2011). These considerations are especially important in very young pediatric patients, who are not simply small in terms of total body size or surface area. They differ in terms of organ function capacity, ontogeny and maturation, all of which can affect pharmacokinetic processes in a nonlinear manner, and consequently lead to differences in systemic and target tissue exposure (Cella et al., 2010b; Rodieux et al., 2015). Such a nonlinearity implies that the use of dosing recommendations on a milligram per kilogram basis $(\mathrm{mg} / \mathrm{kg})$ does not necessarily correct for the underlying differences in pharmacokinetics.

Yet, efficacy findings supporting dose recommendations have often overlooked the importance of exposure and pharmacokinetic-pharmacodynamic data (Zaidi et al., 2013a; Baqui et al., 2015). In this regard, it is important to underline that the antibacterial activity of gentamicin is concentrationdependent, as expressed by the ratio of peak plasma concentration over the minimum inhibitory concentration $\left(C_{\max }: M I C\right)$, which should exceed 8-10 for optimal efficacy (Moore et al., 1987; Levison and Levison, 2009). Nevertheless, attainment and maintenance of target levels may be challenging in preterm and term newborn infants, as changes in organ function occur relatively fast. Gentamicin is essentially eliminated by renal excretion through glomerular filtration and as such its elimination is determined by nephrogenesis, which reaches completion between 32 and 36 weeks of gestation (Rodriguez et al., 2004; Schreuder et al., 2011). In addition, gentamicin disposition is affected by distributional differences, such as extracellular body water and changes in renal blood flow. During the first weeks of life, there is a progressive rise in glomerular filtration rate (GFR) resulting from an acute increase in cardiac output induced by a decrease in renal vascular resistance (Vanpee et al., 1992; Andersen et al., 2012). Consequently, renal elimination of gentamicin in neonates is largely linked to both gestational age and post-natal (PNA) age.

The selection of a dose and dosing regimen for the neonatal population should therefore account for the effect of maturation (increase in age and function) and growth (increase in size). Ultimately, we envisage the possibility of deriving simplified fixed dose regimens for intramuscular gentamicin, which will facilitate prescription and dispensation practice in a resource-limited setting whilst minimizing the risk of under and overexposure of preterm and term neonates to antibiotics.

\section{MATERIALS AND METHODS}

\section{Clinical Data}

Demographic and clinical response data from patients who were enrolled into the AFRINEST and SATT trials were used as reference for the purpose of the current investigation. The availability of these data allows for resampling of relevant covariates taking into account actual distributions and correlations between demographic and clinical baseline characteristics. As shown in Supplementary Figure S1, data for post-natal age presents a skewed distribution, which adequately reflects the epidemiologic characteristics of sepsis after birth. An overview of the demographic variables included in the analysis is presented in Table 1. Further details of the trial 
TABLE 1 | Demographic characteristics of the pediatric patients enrolled in the AFRINEST and SATT trials (Zaidi et al., 2013b; African Neonatal Sepsis Trial et al., 2015; Baqui et al., 2015), which were used in subsequent simulation scenarios.

\section{Patient characteristics}

Number of patients

Post-natal age (days), median (range)

Male, \%
Weight $(\mathrm{kg})$, median (range)
Value

10,840

$16(1-59)$

$3.3(1.5-8)$

51 protocols are available elsewhere (Zaidi et al., 2013b; African Neonatal Sepsis Trial et al., 2015; Baqui et al., 2015). The studies have been conducted in full conformance with the principles of the Declaration of Helsinki and with the local laws and regulations concerning clinical trials.

\section{Virtual Population Cohort}

The baseline data were used to create a virtual cohort with similar characteristics of the pediatric patients enrolled in the AFRINEST and SATT trials. Of interest were the demographic characteristics which have been identified as influential covariates on disposition parameters. As information on gestational age (GA) was not available for individual patients in the clinical trials, GA was imputed from post-menstrual age (PMA), body weight (BW) and gender using the approach described by Sumpter and Holford (Sumpter and Holford, 2011). The method relies on the assumption of a correlation between actual body weight, weight at birth and gestational/ post-natal age. To prevent spurious variability in subsequent simulation steps and avoid combinations of individual BW and GA which might not be biologically plausible, each individual patient was assigned a GA value that corresponded to the median of the predicted GA distribution for the patient's body weight. Subsequently, the proportion of preterm infants with imputed GA between 24 and 36 weeks was compared with epidemiological data describing the prevalence of preterm births (Tucker and McGuire, 2004; Chawanpaiboon et al., 2019), which occur on average in $12 \%$ of the population. In addition, predicted values were further compared against data describing the incidence of sepsis between birth and 59 days (Waters et al., 2011; Blencowe et al., 2013; Downie et al., 2013). An overview of the correlations between body weight, GA and PNA for preterm and term newborns and infants is shown in Supplementary Figure S2.

\section{Pharmacokinetic Model Selection}

The search strategy for model selection included the following keywords and MESH terms in PubMed: "gentamicin," "pharmacokinetics," "model," "sepsis," "neonates" and/or "infants." Three important criteria were used for inclusion of publications, namely, 1) Comparable demographics to the population in our analysis, 2) No confounding comorbidity or comedications and 3) Internal and external validation procedures. An additional exclusion criteria regarded the choice of parameterization used to describe the disposition properties of gentamicin. Models based on empirical parameterization were deemed unsuitable for prospective simulations. Initially, five candidate models were identified that seemed relevant for the purposes of the current investigation (Supplementary Table S1). However, after careful review of the publications only the model proposed by Fuchs and colleagues appeared to satisfy all the predefined inclusion and exclusion criteria (Fuchs et al., 2014). Moreover, the model was developed using a very large population including newborns and infants from 24 to 42 weeks gestational age (namely, 994 preterm and 455 term newborns). Such a large population ensured parameter estimates with higher precision, as well as accurate characterisation of the interindividual variability in disposition characteristics in this group of patients.

In brief, Fuchs and colleagues have identified a twocompartment pharmacokinetic model to describe the disposition of gentamicin in preterm and term neonatal patients following intravenous administration over a 30 min infusion, most of the time in association with amoxicillin. Model evaluation was based on standard graphical and statistical criteria and included external validation procedures. The average parameter estimates and corresponding betweensubject variability (BSV\%) for a median body weight of $2.17 \mathrm{~kg}$ were $0.089 \mathrm{~L} / \mathrm{h}(28 \%)$ for clearance $(\mathrm{CL})$ and $0.908 \mathrm{~L}$ (18\%) for the central volume of distribution $(\mathrm{Vc})$. Body weight, gestational age and post-natal age positively influenced CL, whereas body weight and gestational age positively influenced the volume of distribution of the central compartment (Figure 1; Supplementary Table S2 for details on the pharmacokinetic parameter estimates). To ensure that model parameters and covariate-parameter correlations were coded correctly, an initial evaluation was performed to assess model performance. The model by Fuchs et al. was used to simulate gentamicin plasma concentrations in sepsis patients described in Thomson et al. (Thomson et al., 2003).

Subsequently, the generalisability of the pharmacokinetic model for the simulation of gentamicin concentration vs. time profiles was assessed in a population that reflects real-world conditions. An additional evaluation, from now on referred to as secondary external validation was performed using therapeutic drug monitoring data collected in subjects with or without sepsis at the Robert Debré Children's Hospital, Paris, as part of therapeutic drug monitoring. Initially, 37 plasma samples from 29 subjects with comparable demographic baseline characteristics, who were treated with standard gentamicin intravenous doses were retrieved for the secondary external validation. Of these, one subject was excluded from the data set because of inaccurate details on the reported dosing regimen. An overview of the demographic variables of the subjects used for model building in Fuchs et al. and for the secondary external validation is presented in Table 2. For the evaluation of model performance, post-hoc parameter estimates were obtained for each subject in the secondary external validation data set by using the MAXEVAL = 0 option. Then, goodness-of-fit (GOF), visual predictive checks (VPC) and model prediction error (MPE) were assessed. The VPC was generated using 1,000 simulations. Median and $90 \%$ 


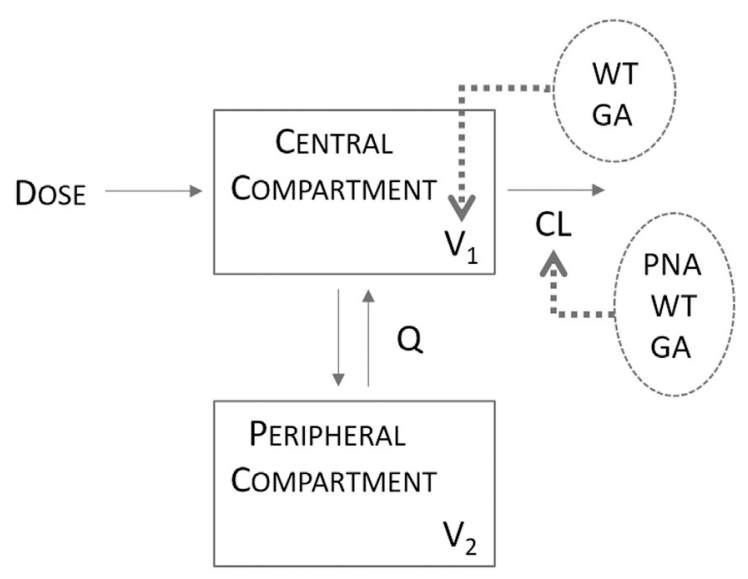

\section{Deterministic model parameters}

$V_{1}$-Volume of distribution (central compartment)

$\mathrm{V}_{2}$ - Volume of distribution (peripheral compartment)

$\mathrm{Q}$ - Inter-compartmental clearance

$\mathrm{CL}$ - Clearance

\section{Covariate factors}

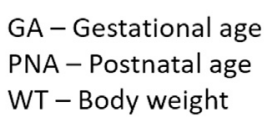

GA - Gestational age

WT - Body weight

FIGURE 1 | Population pharmacokinetics of gentamicin in a large cohort of preterm and term neonates, as described by Fuchs et al. (2014) Absorption was assumed to be instantaneous and suitable for the description of gentamicin profiles following intramuscular administration.

TABLE 2 | Demographic characteristics of patients used for model building and secondary external validation.

\begin{tabular}{lcc}
\hline Patient characteristics & Model building * & $\begin{array}{c}\text { Secondary external } \\
\text { validation }\end{array}$ \\
\hline $\begin{array}{l}\text { Number of patients } \\
\text { Gestational age (weeks), median } \\
\text { (range) }\end{array}$ & $34(24-42)$ & 28 \\
$\begin{array}{l}\text { Post-natal age (days), median } \\
\text { (range) }\end{array}$ & $1(0-94)$ & $47(24.7-41)$ \\
$\begin{array}{l}\text { Post-menstrual age (weeks), } \\
\text { median (range) }\end{array}$ & $34.4(24.2-42.4)$ & $37(25.9-60)$ \\
$\begin{array}{l}\text { Weight (kg), median (range) } \\
\text { Male, \% }\end{array}$ & $2.2(0.4-5.5)$ & $2.9(0.6-4.5)$ \\
& 57.5 & 54
\end{tabular}

*Values from model building are adapted from Fuchs et al. (2014) with permission.

confidence intervals of the simulated values were calculated for each subject and plotted together with the observed data. The mean percentage error (MPE) was calculated according to the following formula:

$$
\operatorname{MPE}(\%)=\frac{I P R E D-D V}{D V} \cdot 100
$$

where IPRED is the individual predicted concentration and DV is the observed concentration.

In addition, the positive predicted value (PPV) and the negative predicted value (NPV) were calculated to evaluate the ability of the model to correctly predict trough concentrations below the safety threshold $(2 \mathrm{mg} / \mathrm{L})$. Finally, the secondary parameters of interest ( $A U C, \mathrm{C}_{\max }$ and $\mathrm{C}_{\min }$ ) were derived from the predicted pharmacokinetic profiles using noncompartmental methods.

\section{Simulation Assumptions}

As the current evaluation is part of a broader investigation aimed to identify the feasibility of simplified regimens for first line antibiotics for the treatment of severe bacterial infections when referral is not possible, a common set of assumptions has been used for each of the drugs in scope. As presented previously by D'Agate and colleagues for amoxicillin (D'Agate et al., 2020), six key assumptions were required for the assessment and interpretation of the results, namely:

(1) Treatment failure was assumed to be linked to pharmacokinetic variability (i.e., underexposure), rather than resistance (Roberts and Lipman, 2006).

(2) Correlations between patient demographic characteristics and physiological processes that determine interindividual differences in drug disposition were considered to be constant across the course of disease, unless stated otherwise.

(3) The absorption rate of gentamicin after intramuscular administration was deemed to be very fast and as such for modeling purposes, dose was assumed to be delivered directly into the central compartment, as per parenteral administration. This assumption is supported by previous investigations, which have shown comparable disposition profiles of gentamicin after intramuscular and intravenous administration (Hayani et al,, 1997; Gemer et al., 2001). In addition, Seaton et al. and Thomson et al. both showed that a first order absorption 


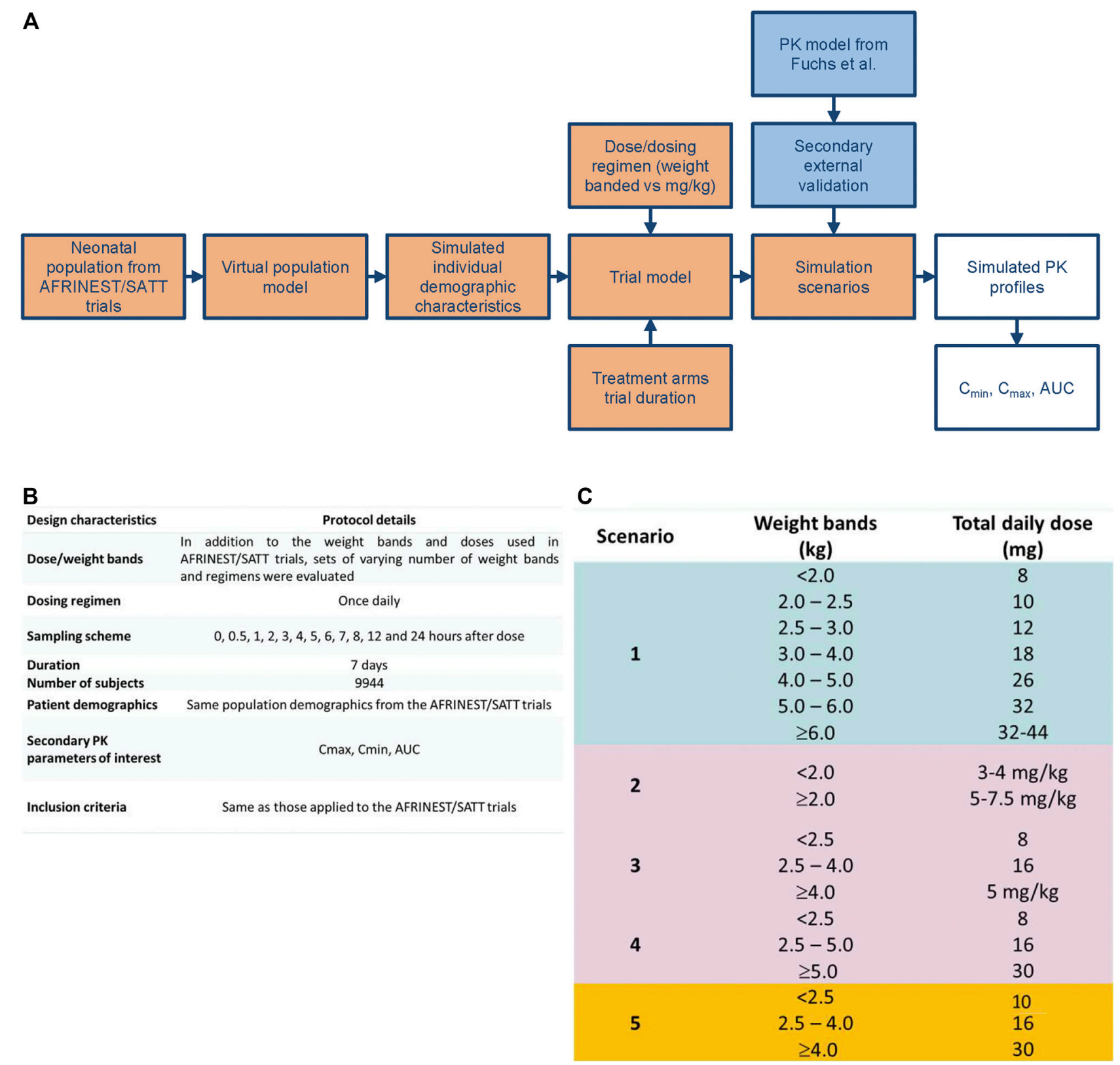

FIGURE 2 | (A) Workflow for the implementation of clinical trial simulations aimed at the evaluation of simplified dosing regimens for gentamicin in neonatal sepsis. (B) Design characteristics for the study protocol used in the clinical trial simulations. (C) Simulation scenarios evaluated for the identification of a simplified dosing regimen based on weight bands and fixed doses.

model does not describe intramuscular pharmacokinetic data in infants and children (Thomson et al., 2003; Seaton et al., 2007).

(4) Dose proportionality (i.e., pharmacokinetic linearity) was assumed beyond the observed range of doses and concentrations if higher doses (i.e., up to two-fold) were used in simulation scenarios.

(5) Differences of up to $10 \%$ in median secondary pharmacokinetic parameter estimates (AUC, $\mathrm{C}_{\max }$, and $\mathrm{C}_{\min }$ ) were not deemed clinically relevant. Such a variation allows for the effect of model uncertainty whilst taking into account the impact of changes in dosage forms, as defined by current regulatory guidelines, which permit even larger variation when evaluating whether different formulations are bioequivalent.

(6) Treatment adherence was assumed to vary randomly and to be dose-independent for the purposes of simulations.

\section{Simulation Scenarios-In Silico Clinical Trial Protocol}

Gentamicin exposure following once daily intramuscular administration was simulated in a virtual cohort $(n=9,994)$ of 
preterm and term newborns and infants with post-natal age varying from 0 to 59 days. In addition to the effect of demographic covariates simulation scenarios have also accounted for the skewed distributions in age and body weight, which reflects the incidence and prevalence of sepsis in this population. An outline of the simulation steps and selected scenarios for the identification of a simplified regimen are summarized in Figure 2. The currently recommended dosing regimen by WHO was used as reference scenario for the purpose of comparisons between regimens (World Health Organization, 2015).

The parameters of interest included the peak concentration $\left(\mathrm{C}_{\max }\right)$ and the trough concentration $\left(\mathrm{C}_{\min }\right)$ associated with once daily gentamicin administration. In addition, the area under the curve (AUC) was calculated to compare exposure across weight and age groups in the population as this parameter correlates with the total dose delivered, which is currently given in $\mathrm{mg} / \mathrm{kg}$. Given that gentamicin is delivered intramuscularly and absorption is rapid, formulation was not considered a significant source of variability in the simulation scenarios (Thomson et al., 2003).

All simulation scenarios were based on the use of once daily doses of gentamicin for a period of 7 days. Pharmacokinetic sampling was implemented according to a typical sampling scheme with one pre-dose and 11 post-dose samples (Figure 2). Even though optimization techniques have not been applied, the selected sampling intervals were assumed to allow accurate estimation of AUC over the dosing interval as well as identification of peak and through levels of gentamicin. $\mathrm{C}_{\max }$ and $\mathrm{C}_{\min }$ were calculated, respectively, by taking the maximum predicted concentration and the predicted pre-dose concentration after the first dose and at steady state conditions at the end of treatment. For the sake of comparison, integration of the concentration vs. time data according to the trapezoidal rule was applied for the calculation of the AUC. All simulations were performed using NONMEM version 7.3 (ICON Development Solutions, Ellicott City, MD, United States). R version 3.1.2 (R Core Team, 2013) was used to graphically summarize the results.

Threshold values for target peak and trough concentrations were selected for comparison of the performance of the different dosing regimens taking into account pharmacokineticpharmacodynamic indices as well as microbiological susceptibility data, safety and efficacy results from available clinical studies. A cut-off value of $10 \mathrm{mg} / \mathrm{L}$ was used for peak concentrations and $2 \mathrm{mg} / \mathrm{L}$ for trough concentrations. These thresholds were used as a proxy for efficacy and safety, respectively. Consequently, the selected regimens aimed at maximizing the proportion (in percentage, \%) of sepsis patients aged 0-59 days with peak concentrations above the reference threshold level of $10 \mathrm{mg} / \mathrm{L}$, whilst minimizing those below the $2 \mathrm{mg} / \mathrm{L}$ threshold for trough concentrations. The reference thresholds were based on recommendations from the British National Formulary (https://bnf.nice.org.uk/drug/gentamicin.html) and a comprehensive review on the use of gentamicin for the treatment of suspected or proven sepsis (Rao et al., 2015; Ibrahim et al., 2016). Given the aforementioned criteria, no formal hypothesis test was used to compare scenarios. Each scenario was summarized taking into account the weight bands associated with the corresponding scenario. Median estimates were calculated along with the $90 \%$ confidence intervals for the parameters of interest.

\section{RESULTS}

Our analysis shows how doses and dosing regimens can be evaluated in a systematic manner, considering the contribution of factors known to affect drug disposition in the neonatal patient population. In addition to the selected simplified regimen, two scenarios are discussed: 1) the performance of the dosing regimens used in AFRINEST and SATT studies and 2) the 2015 WHO recommendations for management of possible serious bacterial infections in young infants 0-59 days old when referral is not feasible (World Health Organization, 2015). Predicted concentration vs. time profiles, peak and through concentrations in the AFRINEST and SATT studies were used as basis for further assessment and interpretation of the role of interindividual variability in drug disposition in the neonatal population.

\section{Model Performance and Secondary External Validation}

The secondary external validation procedures showed that model predictions for trough concentrations are associated with a median MPE of $-7.7 \%$. This was slightly higher than the median MPE reported for the external validation in Fuchs et al. (i.e., -3\%). Clearly, the higher variability observed for the MPE in this group of patients reflects the heterogeneity of the pediatric population. Yet, the model showed adequate performance, predicting correctly whether a trough concentration is below the threshold for safety $(2 \mathrm{mg} / \mathrm{L})$ with a PPV of 0.94 and an NPV of 0.87 .

The goodness-of-fit plots for the secondary external validation data set are shown in Supplementary Figure S3, together with the data from the external validation performed by Fuchs et al. These plots indicate comparable model performance for the different data sets, but with a higher unexplained variability. An overview of the concentration vs. time profiles is depicted in Supplementary Figure S4, where the individual VPCs show the predictive performance of the model, especially for lower concentrations. The predicted median AUC was $110 \mathrm{mg} \mathrm{h} / \mathrm{L}$ (90\% CI 49-129 mg h/L), $\mathrm{C}_{\max }$ was $14.4 \mathrm{mg} / \mathrm{L}(90 \% \mathrm{CI} 10.6-20.9 \mathrm{mg} / \mathrm{L})$ and $\mathrm{C}_{\min }$ was 0.66 (90\% CI $0.07-2.58 \mathrm{mg} / \mathrm{L})$.

\section{Predicted Gentamicin Exposure in the AFRINEST and SATT Studies}

Despite the use of six weight bands to account for the effect of body weight, the median exposure to gentamicin, expressed as the area under concentration vs. time curve, was found to vary by more than $50 \%$ across the different groups (Figure 3). Whilst 


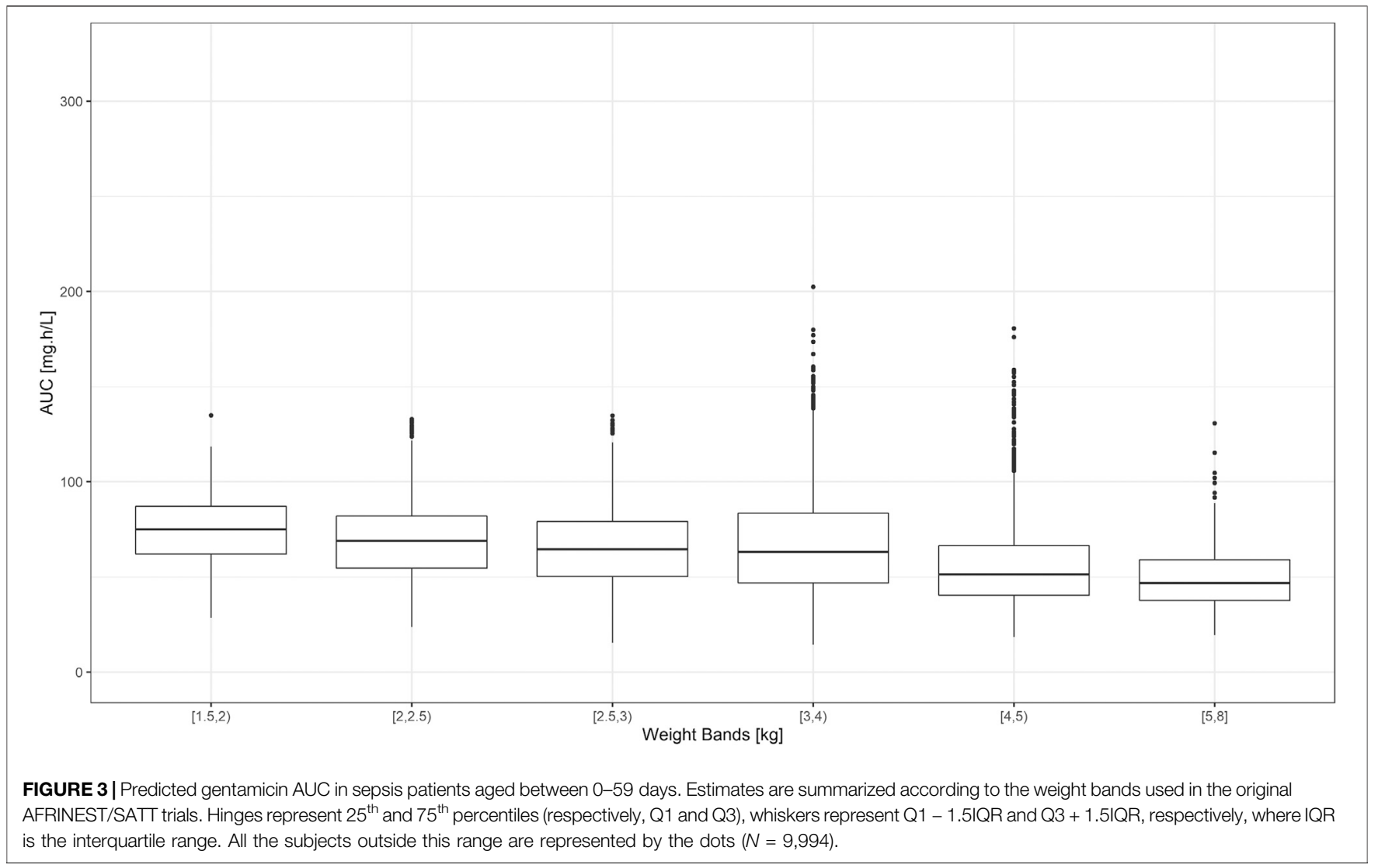

most subjects appear to achieve target peak and trough concentrations of gentamicin, considerable fluctuation in drug levels was observed across the different weight bands. Target concentrations are not achieved in a small proportion of subjects in the lower weight bands.

An overview of the variability in the predicted peak and trough concentrations of gentamicin is shown in Figure 4, where $C_{\max }$ and $\mathrm{C}_{\min }$ values are summarized after the first dose of a once daily dosing regimen over a period of 7 days. Data were stratified by weight bands, as per protocol. In addition, the predicted percentage (\%) of sepsis patients with peak concentrations below the reference threshold level of $10 \mathrm{mg} / \mathrm{L}$ and trough concentrations above $2 \mathrm{mg} / \mathrm{L}$ is summarized in Table 3.

\section{Comparison Between the Proposed Simplified Regimen and the WHO Recommendations}

In contrast to current guidelines, which recommend the use of gentamicin in $\mathrm{mg} / \mathrm{kg}$, our analysis demonstrates the feasibility of implementing a fixed dose regimen based on three weight bands. Figure 5 shows the population predicted plasma concentration vs. time profile of gentamicin for the proposed simplified regimen along with the $90 \%$ confidence intervals, as compared to the 2015 WHO recommended doses of $5.0-7.5 \mathrm{mg} / \mathrm{kg}$. As it can be observed, the two regimens seem to overlap considerably with each other.
Summary statistics of the two main secondary parameters $\left(\mathrm{C}_{\max }\right.$ and $\left.\mathrm{C}_{\min }\right)$ are presented along with the $90 \%$ confidence intervals in Table 4. An overview of the variability in the predicted peak and trough concentrations of gentamicin is shown in Figure 6, where data are stratified by weight bands. It is clear from the results that despite correction for differences in body weight, considerable variation is observed between lower and upper weight ranges. Given the possibility of selecting gentamicin doses between 5.0 and $7.5 \mathrm{mg} / \mathrm{kg}$, some children remain significantly below the target threshold for peak concentrations, whilst others exceed the threshold of $2 \mathrm{mg} / \mathrm{L}$. As can be seen from Table 3, the proposed simplified regimen represents an opportunity for dose optimization not only with respect to the current WHO recommended doses, but also when considering more complex regimens, as those implemented in the AFRINEST/SATT trials.

Of note are the changes in disposition characteristics in preterm low weight newborns and infants, especially for subjects between 1.5 and $2.0 \mathrm{~kg}$, as doses of $3.0 \mathrm{mg} / \mathrm{kg}$ lead to a significant proportion of subjects below the target peak concentration. The proposed regimen practically eliminates the problem, with all subjects reaching $C_{\max }$ values greater than $10 \mathrm{mg} / \mathrm{L}$. However, an increase in the proportion of subjects with $\mathrm{C}_{\max }>2 \mathrm{mg} / \mathrm{L}$ is also observed. The $95 \%$ percentile of $\mathrm{C}_{\text {min }}$ in this subgroup of subjects is $2.45 \mathrm{mg} / \mathrm{L}$.

In addition, to assess the implications of the different regimens, data were also presented using narrower weight bands (Supplementary Figure S5). Our results reveal that a 


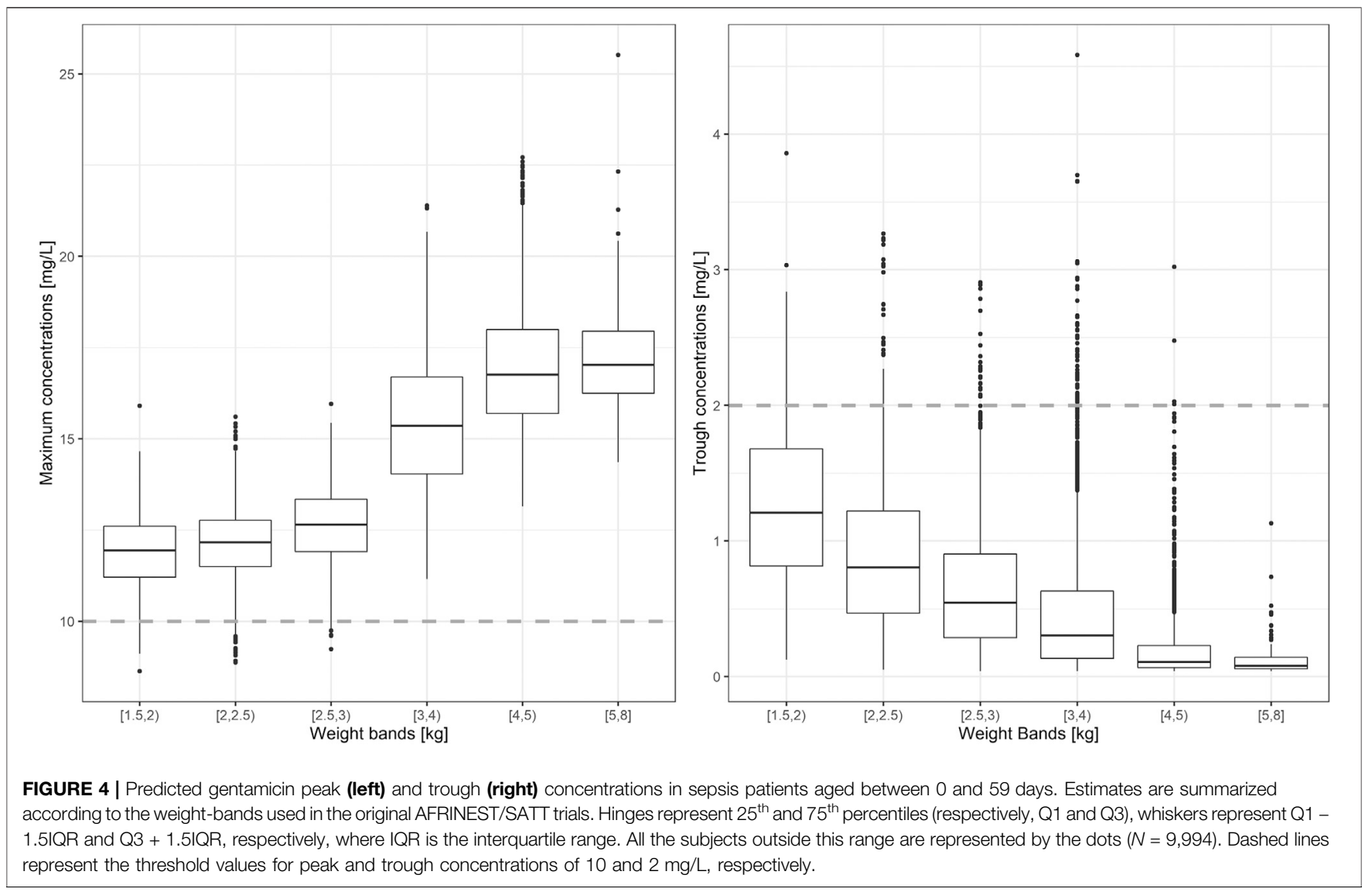

TABLE 3 | Predicted percentage (\%) of sepsis patients aged 0-59 days with peak concentrations below the reference threshold level of $10 \mathrm{mg} / \mathrm{L}$ and trough concentrations above $2 \mathrm{mg} / \mathrm{L}$ after a once daily dosing regimen of gentamicin.

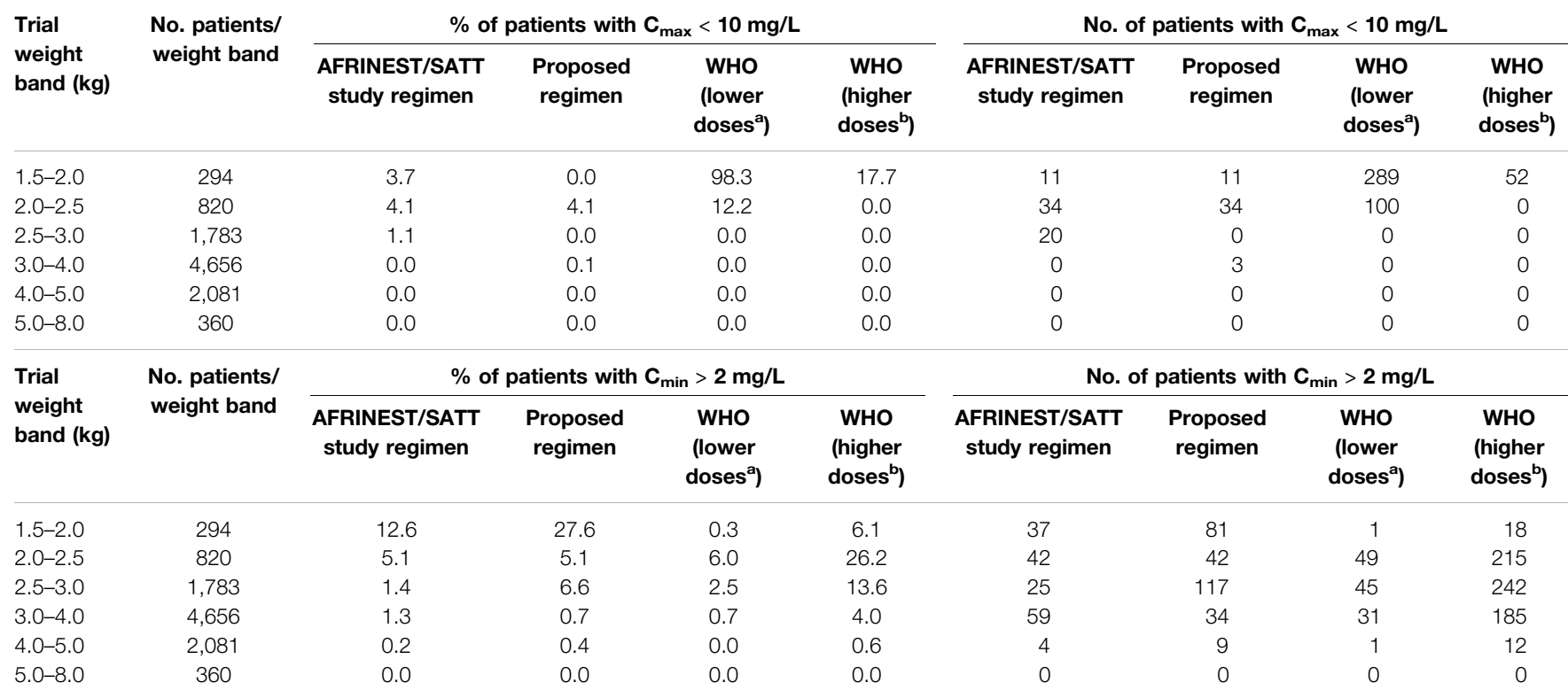

${ }^{a}$ Lower doses are $3 \mathrm{mg} / \mathrm{kg}$ for low birth weight $(<2.0 \mathrm{~kg}$ ) newborns and $5 \mathrm{mg} / \mathrm{kg}$ for those with body weight $>2.0 \mathrm{~kg}$.

${ }^{b}$ Higher doses are $4 \mathrm{mg} / \mathrm{kg}$ for low birth weight newborns and $7.5 \mathrm{mg} / \mathrm{kg}$ for those with body weight $>2.0 \mathrm{~kg}$.

Data are summarized according to the weight bands used in the trials. 

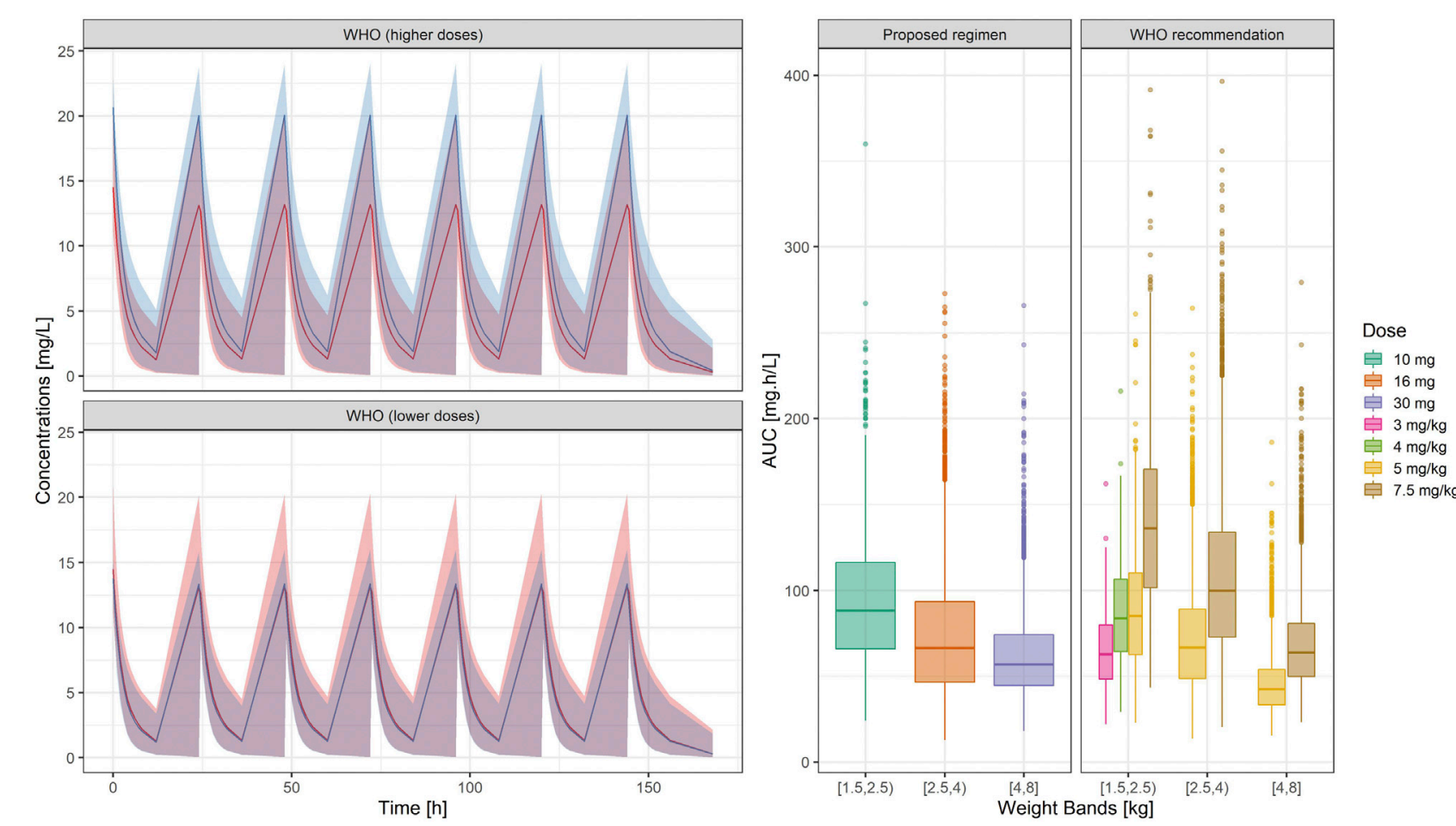

FIGURE 5 | (Left) Predicted gentamicin concentration vs. time profile in sepsis patients aged between 0 and 59 days. Each panel compares the pharmacokinetic profiles in the target population after the proposed regimen (red) with those obtained after higher (upper panel) and lower doses (lower panel) of the WHO recommended regimen (blue). Solid line depicts the median profile; shaded area represents the 90\% prediction intervals. Time 0 is used as reference for the first dose (Right) Systemic exposure, expressed as area under the concentration vs. time curve. Hinges represent $25^{\text {th }}$ and $75^{\text {th }}$ percentiles (respectively, Q1 and Q3), whiskers represent Q1 $1.5 \mathrm{IQR}$ and Q3 $+1.5 \mathrm{IQR}$, respectively, where IQR is the interquartile range. All the subjects outside this range are represented by the dots $(N=9,994)$. Overall, the weight-banded regimens result in similar exposure ranges, with a slight trend to lower values in the highest weight band.

TABLE 4 | Predicted peak $\left(\mathrm{C}_{\max }\right)$ and trough $\left(\mathrm{C}_{\mathrm{min}}\right)$ concentrations of gentamicin after a once daily dosing regimen.

\begin{tabular}{|c|c|c|c|c|c|c|c|c|}
\hline \multirow{2}{*}{$\begin{array}{l}\text { Weight } \\
\text { band } \\
(\mathbf{k g})\end{array}$} & \multicolumn{4}{|c|}{$\mathrm{C}_{\max }(\mathrm{mg} / \mathrm{L})$} & \multicolumn{4}{|c|}{$C_{\min }(\mathrm{mg} / \mathrm{L})$} \\
\hline & $\begin{array}{c}\text { AFRINEST/SATT } \\
\text { study } \\
\text { regimens }\end{array}$ & $\begin{array}{l}\text { Proposed } \\
\text { regimen }\end{array}$ & $\begin{array}{c}\text { WHO (lower } \\
\text { doses }^{\text {a) }}\end{array}$ & $\begin{array}{c}\text { WHO (higher } \\
\text { doses }^{\text {b) }}\end{array}$ & $\begin{array}{l}\text { AFRINEST/ } \\
\text { SATT study } \\
\text { regimens }\end{array}$ & $\begin{array}{l}\text { Proposed } \\
\text { regimen }\end{array}$ & $\begin{array}{c}\text { WHO (lower } \\
\text { doses }^{\text {a) }}\end{array}$ & $\begin{array}{c}\text { WHO (higher } \\
\text { doses }^{\text {b }} \text { ) }\end{array}$ \\
\hline $1.5-2.5$ & $12.37(10.2,14.88)$ & $12.8(10.46,17.33)$ & 12.(7.35, 15.69) & $20(10.06,23.6)$ & $0.9(0.2,2.15)$ & $0.96(0.2,2.45)$ & $0.82(0.19,1.93)$ & $1.24(0.3,3.04)$ \\
\hline $2.5-4.0$ & $14.55(11.58,18.28)$ & $14.49(11.27,18.47)$ & $14.48(12.44,16.34)$ & $21.73(18.66,24.51)$ & $0.37(0.06,1.48)$ & $0.37(0.06,1.64)$ & $0.36(0.06,1.47)$ & $0.52(0.08,2.19)$ \\
\hline $4.0-8.0$ & $16.82(14.48,20.07)$ & 18.(15.38, 23.1) & $13.79(12.7,16.02)$ & $20.69(19.05,24.03)$ & $0.1(0.04,0.67)$ & $0.11(0.04,0.75)$ & $0.09(0.04,0.57)$ & $0.12(0.05,0.79)$ \\
\hline
\end{tabular}

Values shown are the median, $5^{\text {th }}$ and $95^{\text {th }}$ percentiles.

a Lower doses are $3 \mathrm{mg} / \mathrm{kg}$ for low birth weight $(<2.0 \mathrm{~kg}$ ) newborns and $5 \mathrm{mg} / \mathrm{kg}$ for those with body weight $>2.0 \mathrm{~kg}$.

${ }^{b}$ Higher doses are $4 \mathrm{mg} / \mathrm{kg}$ for low birth weight newborns and $7.5 \mathrm{mg} / \mathrm{kg}$ for those with body weight $>2.0 \mathrm{~kg}$.

considerable number of patients $<2 \mathrm{~kg}$ appear to remain below the target threshold for peak concentrations following a $3.0 \mathrm{mg} / \mathrm{kg}$ dose. This situation is corrected by the proposed simplified regimen. Whereas the difference between the proposed regimen and WHO recommendations are small, heterogeneity in renal maturation may drive the variation observed in trough levels in newborns with body weight between 2.0 and $2.5 \mathrm{~kg}$. The simplified regimen presented in Table 5 is therefore preferable and should be used as final recommendation for the treatment of neonatal sepsis.

\section{DISCUSSION AND CONCLUSION}

Currently, the WHO recommends the use of gentamicin in combination with ampicillin or amoxicillin as empirical therapy for sepsis in newborns and infants (0-59 days old) (World Health Organization, 2015). Recent clinical trials in this vulnerable population, such as AFRINEST and SATT have shown promising findings, in that high efficacy rates have been achieved with a dosing regimen that can be implemented 

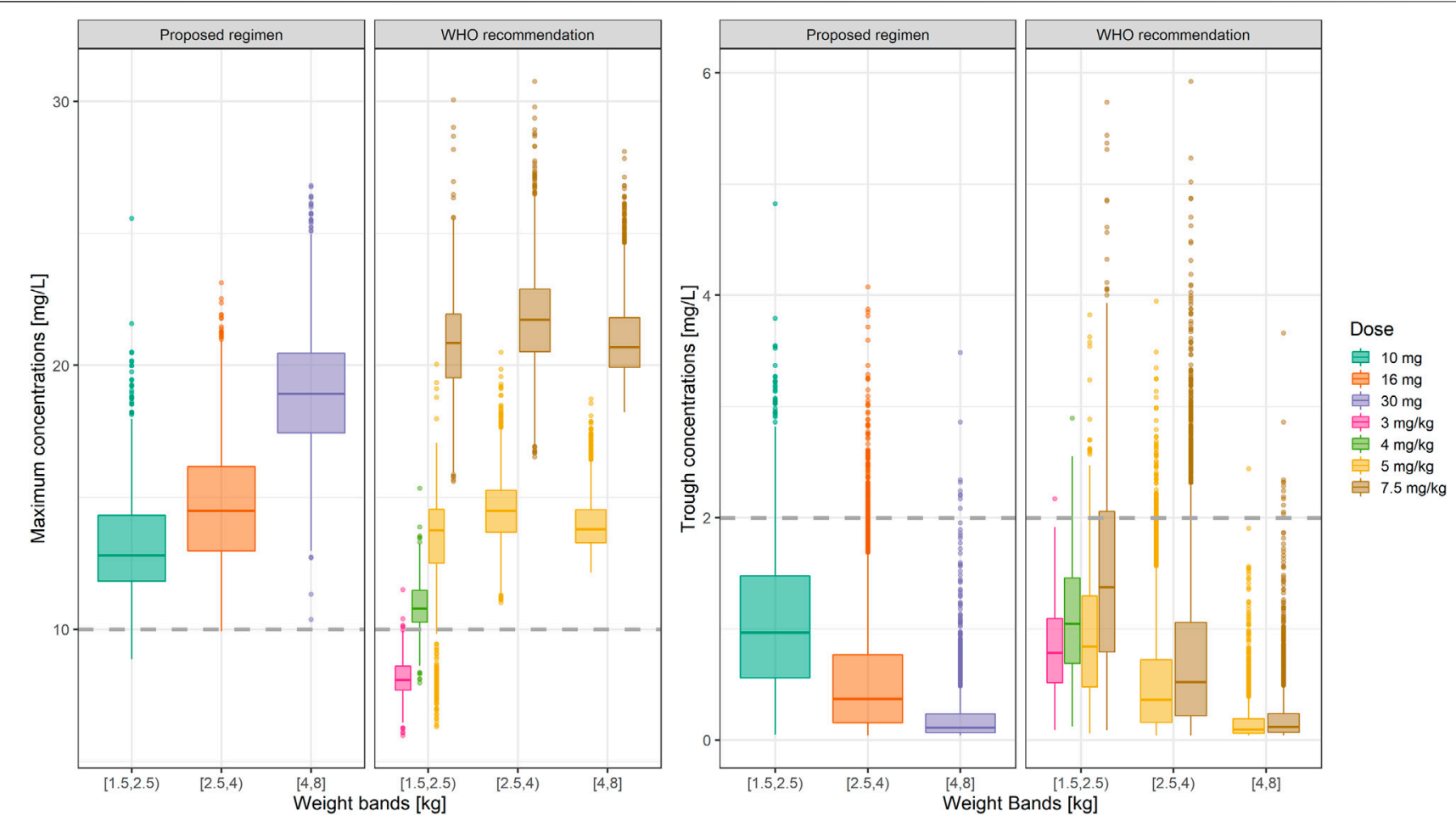

FIGURE 6 | Predicted gentamicin peak (left) and trough (right) concentrations in sepsis patients aged between 0 and 59 days stratified according to the weight bands for the proposed simplified regimen. Panels show how the simplified regimen compares to the $2015 \mathrm{WHO}$ recommendations. Hinges represent $25^{\text {th }}$ and $75^{\text {th }}$ percentiles (respectively, Q1 and Q3), whiskers represent Q1 - 1.5IQR and Q3 + 1.5IQR, respectively, where IQR is the interquartile range. All the subjects outside this range are represented by the dots $(N=9,994)$. Dashed lines represent the threshold values for peak and trough concentrations of 10 and 2 mg/L, respectively.

TABLE 5 | Proposed simplified regimen based on fixed doses of gentamicin for the treatment of sepsis patients aged between 0 and 59 days.

\begin{tabular}{lccc}
$\begin{array}{l}\text { Weight } \\
\text { band }\end{array}$ & $\begin{array}{c}\text { Body } \\
\text { weight } \\
\text { range (kg) }\end{array}$ & $\begin{array}{c}\text { Simplified } \\
\text { regimen }(\mathbf{m g})\end{array}$ & $\begin{array}{c}\text { Volume of gentamicin } \\
\mathbf{4 0} \mathbf{~ m g} / \mathbf{m l} \\
\text { administered per } \\
\text { dose (m) }\end{array}$ \\
\hline 1 & $1.5-2.5$ & 10 & 0.25 \\
2 & $>2.5-4.0$ & 16 & 0.40 \\
3 & $>4.0-8.0$ & 30 & 0.75 \\
\hline
\end{tabular}

in community-based settings (Zaidi et al., 2013a; Zaidi et al., 2013b; African Neonatal Sepsis Trial et al., 2015; Baqui et al., 2015). However, the dosing regimens used in these trials remain complex and as such do not warrant compliance in clinical practice (African Neonatal Sepsis Trial Group, 2013). Consequently, response to treatment may not be comparable to that observed during the trials. In fact, the use of $\mathrm{mg} / \mathrm{kg}$ may represent an important hurdle for the implementation of such interventions in a communitybased setting. Here we have shown how increasing understanding of the pharmacokinetics and pharmacokinetic-pharmacodynamic (PKPD) relationships of the antibiotics can be used in conjunction with quantitative clinical pharmacology principles to guide the dose rationale for gentamicin in newborns and infants with sepsis (Vinks et al., 2015; Mehrotra et al., 2016).
Any attempt to optimize dose and simplify dosing regimens will require therefore an alternative, less empirical approach than clinical evidence of efficacy (Khan and Joseph, 2012; Rao et al., 2015). Given that gentamicin exhibits concentration-dependent bactericidal activity and prolonged post-antibiotic effects, it is essential to understand how drug levels vary across different subgroups in the target patient population, such as infants and newborns. Ultimately, it appears that it is the amount of drug (e.g., $\mathrm{C}_{\max }$ relative to the MIC) rather than the dosing frequency that determines the treatment response (van Maarseveen et al., 2016). Therefore, in our analysis, we have used a target threshold for $\mathrm{C}_{\max }$ of $10 \mathrm{mg} / \mathrm{L}$, rather than a range of concentrations or the $\mathrm{C}_{\max } / \mathrm{MIC}$ ratio. This decision allowed for direct assessment of the observed drug levels and potential implications for the overall efficacy and safety profile of gentamicin. Furthermore, the use of this criterion implies that exposure levels can be considered efficacious for susceptible pathogens with MIC values lower or equal to $1 \mathrm{mg} / \mathrm{L}$.

Historically, the dosing regimens used for gentamicin have evolved from multiple daily dosing to extended-interval dosing both in adults and in children (Kent et al., 2014). These regimens have aimed at ensuring that peak blood concentrations are sufficiently high to elicit a therapeutic response while avoiding high trough concentrations, which could be potentially toxic after prolonged treatment (Hoff et al., 2009; Dersch-Mills et al., 2012; Radivoyevitch et al., 
2015). However, pharmacokinetic data in infants exhibits large inter- and intra-individual variability, mainly because of the developmental changes occurring from the first month of life. As a consequence, gentamicin dosing regimens based on $\mathrm{mg} / \mathrm{kg}$ body weight may not fully correct for age-related changes in organ function, composition, maturation and growth (Koren et al., 1985; Salgado et al., 2010; Rodieux et al., 2015).

In contrast to most of the published pharmacokinetic and PKPD data available in the scientific literature (Lingvall et al., 2005; Nielsen et al., 2009; Sherwin et al., 2009; Roberts et al., 2010; Mohamed et al., 2012; Chin et al., 2013; De Cock et al., 2014; Sampson et al., 2014; Valitalo et al., 2015), our investigation has not been limited to a small group of patients. In fact, we have been able to evaluate pharmacokinetic variability across a large patient population, including the impact of demographic baseline covariates and other relevant disease-related factors on the disposition of gentamicin in neonates and infants. Our analysis has included a range of scenarios aimed at demonstrating the feasibility of a simplified dosing regimen with gentamicin, which accounted for relevant sources of variability in pharmacokinetics. Of note is the identification of weight bands that can be used in combination with fixed dose levels, while ensuring acceptable target peak and trough concentrations of gentamicin. Indeed, a simplified regimen that minimizes the proportion of patients below the peak concentration threshold of $10 \mathrm{mg} / \mathrm{L}$, whilst maximizing the proportion of patients below the trough concentration threshold of $2 \mathrm{mg} / \mathrm{L}$ was identified based on the use of three weight bands, namely, $<2.5,2.5-4.0$, and $>4.0 \mathrm{~kg}$. These cut-off values were selected taking into account the weight categories currently used for the other antibiotics indicated for the treatment of sepsis when referral is not possible (Baqui et al., 2015; World Health Organization, 2015). It should be noted that the predicted differences in exposure between the proposed simplified regimen and WHO recommendations are unlikely to be clinically relevant, with exception of patients weighting $<2.5 \mathrm{~kg}$. Our simulations reveal that peak concentrations will be significantly lower in this weight band after the use of gentamicin doses based on the WHO guidelines. Therefore, a dose of $10 \mathrm{mg}$ should be considered for this group of patients, even if this regimen may be associated with trough levels that are slightly above $2 \mathrm{mg} / \mathrm{L}$ (95\% CI: 0.2-2.45).

From a clinical perspective, in addition to demonstrating the feasibility of an alternative regimen for effective treatment of sepsis, our work also illustrates the role of comprehensive clinical trial simulations for the optimization of therapeutic interventions. We have shown how virtual patient cohorts can be created for the evaluation of interindividual differences in pharmacokinetic disposition taking into account the effect of demographic, physiological and clinical factors known to alter the distribution and elimination of gentamicin in newborns and infants (Moore et al., 1987; Roberts and Lipman, 2006; Levison and Levison, 2009; van Maarseveen et al., 2016). Nevertheless, to date none of the existing guidelines and recommendations regarding the dose rationale for gentamicin have been developed taking these factors into account in a strictly quantitative manner. Such an empiricism in the dose rationale cannot be overlooked. Clearly, in some cases, the use of linear dosing algorithms, such as doses in $\mathrm{mg} / \mathrm{kg}$ body weight may result in sub-optimal or undesirable drug levels across the target population (Hansen et al., 2003; Neef et al., 2006; Rocha et al., 2007; Zakova et al., 2014).

We acknowledge that very few studies have evaluated clinical response taking into account pharmacokinetic variability and so far no data on drug levels have been collected after administration of gentamicin in a resource-limited setting (Dersch-Mills et al., 2012). However, we believe that extrapolation of the pharmacokinetic parameters from a hospital setting to out-patient protocols, as described in the current investigation can be performed with sufficient precision to assess the impact of covariates on drug disposition, irrespective of the treatment setting (Thomson et al., 2003; Roberts and Lipman, 2006; Fuchs et al., 2014). As highlighted in previous paragraphs, we also recognize that assumptions need to be made about the role of other intrinsic and extrinsic sources of variability (e.g., compliance, disease severity, age of onset), which were not included in our analysis (Garcia et al., 2006; Thingvoll et al., 2008; Marsot et al., 2012). For example, information about serum creatinine was not available in the AFRINEST and SATT trials data sets, nor was it included as a covariate on gentamicin elimination parameters in the model developed by Fuchs et al. However, changes in clearance due to renal maturation are captured by the maturation function, expressed in terms of the effect of gestational and postnatal age. Obviously, the maturation function cannot explain differences associated with organ impairment, which may exist due to the presence of co-morbidities or complications due to worsening of sepsis. In such cases, doses would need to be adjusted based on the same principles used for renal impairment. We have also had to use predefined correlations between body weight, gestational and postmenstrual age in preterm and term newborns and infants, which may not fully replicate the variation in a real-world setting, where the correlation between body weight, gestational and post-menstrual age may be further affected by other extrinsic factors, such as malnutrition and disease severity (e.g., diarrhea). We anticipate that these limitations should not alter the conclusions drawn from the current analysis. Furthermore, we should highlight that the use of single cut-off value for the selection of the doses for each weight band created a rather stringent criterion for treatment performance, as microbiological susceptibility data would not be available in a setting where referral is not possible. In reality, ranges have been used for $C_{\max }$ (e.g., $8-12 \mathrm{mg} / \mathrm{ml}$ or $6-15 \mathrm{mg} / \mathrm{ml}$ ) along with varying dosing intervals to ensure both peak and trough target levels are achieved in most neonatal patients (Touw et al., 2009; Martínková et al., 2010; Yu et al., 2020). Nevertheless, we recommend the use of sparse sampling schemes in prospective clinical trials to confirm the predicted pharmacokinetic profiles and ensure the effective implementation of the proposed dosing regimen for the treatment of sepsis in newborns and infants.

The reader should be aware that the recent WHO guidelines have been developed taking into account the existing evidence, from clinical practice and randomised clinical trials in neonates (0-28 days old) and young infants (0-59 days old) with severe bacterial infection in resource-limited settings, where families do not accept or cannot access referral care (World Health Organization, 2015). Whereas the goal of such guidelines is to provide clinical guidance on the simplest antibiotic regimens that 
are both safe and effective for outpatient treatment of clinically severe infections in children 0-59 days old, it appears that an opportunity has been missed to ensure that recommendations are supported by a dose rationale based on an integrated analysis of pharmacokinetics and PKPD principles.

In summary, our findings are promising in that a simpler dosing regimen can be implemented in community-based settings. Intramuscular gentamicin can be used as a fixed dose according to a weight-banded regimen. The proposed regimen for neonates and young infants with sepsis aged 0-59 days differs from current guidelines in that it takes into account the effect of body weight, gestational age and post-natal age as determinants of the variability in the pharmacokinetics of gentamicin. A dose rationale that accounts for the role of influential factors on drug disposition represents a major advancement in the treatment of possible serious bacterial infections in resource-limited settings.

\section{DATA AVAILABILITY STATEMENT}

The simulated data sets generated for this study are available on request to the corresponding author.

\section{AUTHOR CONTRIBUTIONS}

SD and FM contributed to the data analysis, presentation of the results and preparation of the manuscript. EJ-A provided the data

\section{REFERENCES}

African Neonatal Sepsis Trial Group (2013). Simplified regimens for management of neonates and young infants with severe infection when hospital admission is not possible: study protocol for a randomized, open-label equivalence trial. Pediatr. Infect. Dis. J. 32 (Suppl. 1), S26-S32. doi:10.1097/INF. 0b013e31829ff7d1

African Neonatal Sepsis TrialTshefu, A., Lokangaka, A., Ngaima, S., Engmann, C., Esamai, F., et al. (2015). Simplified antibiotic regimens compared with injectable procaine benzylpenicillin plus gentamicin for treatment of neonates and young infants with clinical signs of possible serious bacterial infection when referral is not possible: a randomised, open-label, equivalence trial. Lancet 385 (9979), 1767-1776. doi:10.1016/S0140-6736(14)62284-4

Andersen, T. B., Jødal, L., Boegsted, M., Erlandsen, E. J., Morsing, A., Frøkiær, J., et al. (2012). GFR prediction from cystatin $C$ and creatinine in children: effect of including body cell mass. Am. J. Kidney Dis. 59 (1), 50-57. doi:10.1053/j.ajkd. 2011.09.013

Anderson, G. D. (2010). Developmental pharmacokinetics. Semin. Pediatr. Neurol. 17 (4), 208-213. doi:10.1016/j.spen.2010.10.002

Baqui, A. H., Saha, S. K., Ahmed, A. S., Shahidullah, M., Quasem, I., Roth, D. E., et al. (2015). Safety and efficacy of alternative antibiotic regimens compared with 7 day injectable procaine benzylpenicillin and gentamicin for outpatient treatment of neonates and young infants with clinical signs of severe infection when referral is not possible: a randomised, open-label, equivalence trial. Lancet Glob. Health 3 (5), e279-87. doi:10.1016/S2214-109X(14)70347-X

Bellanti, F., and Della Pasqua, O. (2011). Modelling and simulation as research tools in paediatric drug development. Eur. J. Clin. Pharmacol. 67 (1), 75-86. doi:10.1007/s00228-010-0974-3

Blencowe, H., Cousens, S., Chou, D., Oestergaard, M., Say, L., Moller, A. B., et al. (2013). Born too soon: the global epidemiology of 15 million preterm births. Reprod. Health 10 (Suppl. 1), S2. doi:10.1186/1742-4755-10-S1-S2 for the secondary external validation and contributed to the review of the manuscript. ODP contributed to the discussion of the clinical implication and preparation and review of the manuscript.

\section{FUNDING}

This project has received financial support from Save the Children, United States.

\section{ACKNOWLEDGMENTS}

The authors are thankful to Save the Children for the support and assistance provided for the retrieval of demographic and clinical data from the AFRINEST and SATT trials. We would also like to thank the reviewers for their invaluable contribution to the manuscript. Their queries, concerns and suggestions that have ultimately improved not only the readability but also the robustness and quality of the work presented here.

\section{SUPPLEMENTARY MATERIAL}

The Supplementary Material for this article can be found online at: https://www.frontiersin.org/articles/10.3389/fphar.2021.624662/ full\#supplementary-material.

Buring, J. E., Evans, D. A., Mayrent, S. L., Rosner, B., Colton, T., and Hennekens, C. H. (1988). Randomized trials of aminoglycoside antibiotics: quantitative overview. Rev. Infect. Dis. 10 (5), 951-957. doi:10.1093/clinids/10.5.951

Cella, M., Gorter de Vries, F., Burger, D., Danhof, M., and Della Pasqua, O. (2010a). A model-based approach to dose selection in early pediatric development. Clin. Pharmacol. Ther. 87 (3), 294-302. doi:10.1038/clpt. 2009.234

Cella, M., Knibbe, C., Danhof, M., and Della Pasqua, O. (2010b). What is the right dose for children? Br. J. Clin. Pharmacol. 70 (4), 597-603. doi:10.1111/j.13652125.2009.03591.x

Chan, G. J., Lee, A. C., Baqui, A. H., Tan, J., and Black, R. E. (2013). Risk of earlyonset neonatal infection with maternal infection or colonization: a global systematic review and meta-analysis. PLoS Med. 10 (8), e1001502. doi:10. 1371/journal.pmed.1001502

Chawanpaiboon, S., Vogel, J. P., Moller, A. B., Lumbiganon, P., Petzold, M., Hogan, D., et al. (2019). Global, regional, and national estimates of levels of preterm birth in 2014: a systematic review and modelling analysis. Lancet Glob. Health 7 (1), e37-e46. doi:10.1016/S2214-109X(18)30451-0

Chin, P. K., Florkowski, C. M., and Begg, E. J. (2013). The performances of the Cockcroft-Gault, modification of diet in renal disease study and chronic kidney disease epidemiology collaboration equations in predicting gentamicin clearance. Ann. Clin. Biochem. 50 (6), 546-557. doi:10.1177/0004563213492320

D'Agate, S., Musuamba, F. T., and Della Pasqua, O. (2020). Dose rationale for amoxicillin in neonatal sepsis when referral is not possible. Front. Pharmacol. 11, 521933. doi:10.3389/fphar.2020.521933

De Broe, M. E., Giuliano, R. A., and Verpooten, G. A. (1986). Choice of drug and dosage regimen. Two important risk factors for aminoglycoside nephrotoxicity. Am. J. Med. 80 (6B), 115-118. doi:10.1016/0002-9343(86)90488-2

De Cock, R. F., Allegaert, K., Brussee, J. M., Sherwin, C. M., Mulla, H., de Hoog, M., et al. (2014). Simultaneous pharmacokinetic modeling of gentamicin, tobramycin and vancomycin clearance from neonates to 
adults: towards a semi-physiological function for maturation in glomerular filtration. Pharm. Res. (N. Y.). 31 (10), 2643-2654. doi:10. 1007/s11095-014-1361-z

Dersch-Mills, D., Akierman, A., Alshaikh, B., and Yusuf, K. (2012). Validation of a dosage individualization table for extended-interval gentamicin in neonates. Ann. Pharmacother. 46 (7-8), 935-942. doi:10.1345/aph.1R029

Downie, L., Armiento, R., Subhi, R., Kelly, J., Clifford, V., and Duke, T. (2013). Community-acquired neonatal and infant sepsis in developing countries: efficacy of WHO's currently recommended antibiotics-systematic review and meta-analysis. Arch. Dis. Child. 98, 146-154. doi:10.1136/archdischild2012-302033

Esamai, F., Tshefu, A. K., Ayede, A. I., Adejuyigbe, E. A., Wammanda, R. D., Baqui, A. H., et al. (2013). Ongoing trials of simplified antibiotic regimens for the treatment of serious infections in young infants in South Asia and sub-Saharan Africa: implications for policy. Pediatr. Infect. Dis. J. 32 (Suppl. 1), S46-S49. doi:10.1097/INF.0b013e31829ff941

Evans, D. A., Buring, J., Mayrent, S., Rosner, B., Colton, T., and Hennekens, C. (1986). Qualitative overview of randomized trials of aminoglycosides. Am. J. Med. 80 (6B), 39-43. doi:10.1016/0002-9343(86)90477-8

Fisk, K. L. (1993). A review of gentamicin use in neonates. Neonatal Netw. 12 (7), 19-28. quiz 24-18.

Fuchs, A., Guidi, M., Giannoni, E., Werner, D., Buclin, T., Widmer, N., et al. (2014). Population pharmacokinetic study of gentamicin in a large cohort of premature and term neonates. Br. J. Clin. Pharmacol. 78 (5), 1090-1101. doi:10.1111/bcp. 12444

García, B., Barcia, E., Pérez, F., and Molina, I. T. (2006). Population pharmacokinetics of gentamicin in premature newborns. J. Antimicrob. Chemother. 58 (2), 372-379. doi:10.1093/jac/dkl244

Gemer, O., Harari, D., Mishal, J., and Segal, S. (2001). Comparative pharmacokinetics of once daily intravenous and intramuscular gentamicin in patients with post partum endometritis. Arch. Gynecol. Obstet. 265 (1), 34-35. doi:10.1007/s004040000124

Hansen, A., Forbes, P., Arnold, A., and O'Rourke, E. (2003). Once-daily gentamicin dosing for the preterm and term newborn: proposal for a simple regimen that achieves target levels. J. Perinatol. 23 (8), 635-639. doi:10.1038/sj.jp.7210996

Hayani, K. C., Hatzopoulos, F. K., Frank, A. L., Thummala, M. R., Hantsch, M. J., Schatz, B. M., et al. (1997). Pharmacokinetics of once-daily dosing of gentamicin in neonates. J. Pediatr. 131 (Pt 1), 76-80. doi:10.1016/s00223476(97)70127-6

Hoff, D. S., Wilcox, R. A., Tollefson, L. M., Lipnik, P. G., Commers, A. R., and Liu, M. (2009). Pharmacokinetic outcomes of a simplified, weight-based, extendedinterval gentamicin dosing protocol in critically ill neonates. Pharmacotherapy 29 (11), 1297-1305. doi:10.1592/phco.29.11.1297

Ibrahim, J., Maffei, D., El-Chaar, G., Islam, S., Ponnaiya, S., Nayak, A., et al. (2016). Should gentamicin trough levels be routinely obtained in term neonates? J. Perinatol. 36 (11), 962-965. doi:10.1038/jp.2016.120

Kent, A., Turner, M. A., Sharland, M., and Heath, P. T. (2014). Aminoglycoside toxicity in neonates: something to worry about? Expert Rev. Anti Infect. Ther. 12 (3), 319-331. doi:10.1586/14787210.2014.878648

Khan, S. N., and Joseph, S. (2012). Appropriate use of antibiotics for the management of sepsis in neonates. Int. J. Pharmaceut. Sci. Res. 3, 1928-1934. doi:10.13040/ IJPSR.0975-8232.3

Koren, G., James, A., and Perlman, M. (1985). A simple method for the estimation of glomerular filtration rate by gentamicin pharmacokinetics during routine drug monitoring in the newborn. Clin. Pharmacol. Ther. 38 (6), 680-685. doi:10.1038/clpt.1985.245

Lassi, Z. S., Haider, B. A., and Bhutta, Z. A. (2010). Community-based intervention packages for reducing maternal and neonatal morbidity and mortality and improving neonatal outcomes. Cochrane Database Syst. Rev. 11, CD007754. doi:10.1002/14651858.CD007754.pub2

Lawn, J. E., Blencowe, H., Oza, S., You, D., Lee, A. C., Waiswa, P., et al. (2014). Every newborn: progress, priorities, and potential beyond survival. Lancet 384 (9938), 189-205. doi:10.1016/S0140-6736(14)60496-7

Lee, A. C., Chandran, A., Herbert, H. K., Kozuki, N., Markell, P., Shah, R., et al. (2014). Treatment of infections in young infants in low- and middle-income countries: a systematic review and meta-analysis of frontline health worker diagnosis and antibiotic access. PLoS Med. 11 (10), e1001741. doi:10.1371/ journal.pmed.1001741

Levison, M. E., and Levison, J. H. (2009). Pharmacokinetics and pharmacodynamics of antibacterial agents. Infect. Dis. Clin. 23 (4), 791-815. doi:10.1016/j.idc.2009.06.008

Lingvall, M., Reith, D., and Broadbent, R. (2005). The effect of sepsis upon gentamicin pharmacokinetics in neonates. Br. J. Clin. Pharmacol. 59 (1), 54-61. doi:10.1111/j.1365-2125.2005.02260.x

Liu, L., Johnson, H. L., Cousens, S., Perin, J., Scott, S., Lawn, J. E., et al. (2012). Global, regional, and national causes of child mortality: an updated systematic analysis for 2010 with time trends since 2000. Lancet 379 (9832), 2151-2161. doi:10.1016/S0140-6736(12)60560-1

Manolis, E., and Pons, G. (2009). Proposals for model-based paediatric medicinal development within the current European Union regulatory framework. $\mathrm{Br}$. J. Clin. Pharmacol. 68 (4), 493-501. doi:10.1111/j.1365-2125.2009.03484.x

Marsot, A., Boulamery, A., Bruguerolle, B., and Simon, N. (2012). Population pharmacokinetic analysis during the first 2 years of life: an overview. Clin. Pharmacokinet. 51 (12), 787-798. doi:10.1007/s40262-012-0015-8

Martínková, J., Pokorná, P., Záhora, J., Chládek, J., Vobruba, V., Selke-Krulichová, I., et al. (2010). Tolerability and outcomes of kinetically guided therapy with gentamicin in critically ill neonates during the first week of life: an open-label, prospective study. Clin. Therapeut. 32 (14), 2400-2414. doi:10.1016/j.clinthera. 2011.01.013

Medellín-Garibay, S. E., Rueda-Naharro, A., Peña-Cabia, S., García, B., RomanoMoreno, S., and Barcia, E. (2015). Population pharmacokinetics of gentamicin and dosing optimization for infants. Antimicrob. Agents Chemother. 59 (1), 482-489. doi:10.1128/AAC.03464-14

Mehrotra, N., Bhattaram, A., Earp, J. C., Florian, J., Krudys, K., Lee, J. E., et al. (2016). Role of quantitative clinical pharmacology in pediatric approval and labeling. Drug Metab. Dispos. 44 (7), 924-933. doi:10.1124/dmd.116.069559

Mohamed, A. F., Nielsen, E. I., Cars, O., and Friberg, L. E. (2012). Pharmacokinetic-pharmacodynamic model for gentamicin and its adaptive resistance with predictions of dosing schedules in newborn infants. Antimicrob. Agents Chemother. 56 (1), 179-188. doi:10.1128/AAC.00694-11

Moore, R. D., Lietman, P. S., and Smith, C. R. (1987). Clinical response to aminoglycoside therapy: importance of the ratio of peak concentration to minimal inhibitory concentration. J. Infect. Dis. 155 (1), 93-99. doi:10.1093/ infdis/155.1.93

Neef, C., Touw, D. J., Harteveld, A. R., Eerland, J. J., and Uges, D. R. (2006). Pitfalls in TDM of antibiotic drugs: analytical and modelling issues. Ther. Drug Monit. 28 (5), 686-689. doi:10.1097/01.ftd.0000243966.97964.11

Nielsen, E. I., Sandström, M., Honoré, P. H., Ewald, U., and Friberg, L. E. (2009). Developmental pharmacokinetics of gentamicin in preterm and term neonates: population modelling of a prospective study. Clin. Pharmacokinet. 48 (4), 253-263. doi:10.2165/00003088-200948040-00003

Pandolfini, C., Kaguelidou, F., Sequi, M., Jacqz-Aigrain, E., Choonara, I., Turner, M. A., et al. (2013). Wide intra- and inter-country variability in drug use and dosage in very-low-birth-weight newborns with severe infections. Eur. J. Clin. Pharmacol. 69 (4), 1031-1036. doi:10.1007/s00228-012-1415-2

Pineda, L. C., and Watt, K. M. (2015). New antibiotic dosing in infants. Clin. Perinatol. 42 (1), 167-176. doi:10.1016/j.clp.2014.10.009

Polin, R. A. (2012). Management of neonates with suspected or proven early-onset bacterial sepsis. Pediatrics. 129 (5), 1006-1015. doi:10.1542/peds.2012-0541

R Core Team (2013). R: a language and environment for statistical computing (Vienna, Austria: R Foundation for Statistical Computing). Available: http:// www.R-project.org/ (Accessed November 20, 2020).

Radivoyevitch, T., Siranart, N., Hlatky, L., and Sachs, R. (2015). Stochastic process pharmacodynamics: dose timing in neonatal gentamicin therapy as an example. AAPS J. 17 (2), 447-456. doi:10.1208/s12248-014-9715-3

Rao, S., Abzug, M. J., Carosone-Link, P., Peterson, T., Child, J., Siparksy, G., et al. (2015). Intravenous acyclovir and renal dysfunction in children: a matched case control study. J. Pediatr. 166 (6), 1462-1464. doi:10.1016/j.jpeds.2015. 01.023

Roberts, J. A., Field, J., Visser, A., Whitbread, R., Tallot, M., Lipman, J., et al. (2010). Using population pharmacokinetics to determine gentamicin dosing during extended daily diafiltration in critically ill patients with acute kidney injury. Antimicrob. Agents Chemother. 54 (9), 3635-3640. doi:10.1128/AAC.00222-10 
Roberts, J. A., and Lipman, J. (2006). Antibacterial dosing in intensive care: pharmacokinetics, degree of disease and pharmacodynamics of sepsis. Clin. Pharmacokinet. 45 (8), 755-773. doi:10.2165/00003088-200645080-00001

Roberts, J. K., Stockmann, C., Constance, J. E., Stiers, J., Spigarelli, M. G., Ward, R. M., et al. (2014). Pharmacokinetics and pharmacodynamics of antibacterials, antifungals, and antivirals used most frequently in neonates and infants. Clin. Pharmacokinet. 53 (7), 581-610. doi:10.1007/s40262-014-0147-0

Rocha, M. J., Almeida, A. M., Falcão, A. C., and Caramona, M. M. (2007). Performance of gentamicin population kinetic parameters in Portuguese neonates. Pharm. World Sci. 29 (3), 104-108. doi:10.1007/s11096-007-9109-z

Rodieux, F., Wilbaux, M., van den Anker, J. N., and Pfister, M. (2015). Effect of kidney function on drug kinetics and dosing in neonates, infants, and children. Clin. Pharmacokinet. 54 (12), 1183-1204. doi:10.1007/s40262015-0298-7

Rodríguez, M. M., Gómez, A. H., Abitbol, C. L., Chandar, J. J., Duara, S., and Zilleruelo, G. E. (2004). Histomorphometric analysis of postnatal glomerulogenesis in extremely preterm infants. Pediatr. Dev. Pathol. 7 (1), 17-25. doi:10.1007/s10024-003-3029-2

Salgado, J. V., Neves, F. A., Bastos, M. G., França, A. K., Brito, D. J., Santos, E. M., et al. (2010). Monitoring renal function: measured and estimated glomerular filtration rates-a review. Braz. J. Med. Biol. Res. 43 (6), 528-536. doi:10.1590/ s0100-879x2010007500040

Samardzic, J., Allegaert, K., Wilbaux, M., Pfister, M., and van den Anker, J. N. (2016). Quantitative clinical pharmacology practice for optimal use of antibiotics during the neonatal period. Expet Opin. Drug Metabol. Toxicol. 12 (4), 367-375. doi:10.1517/17425255.2016.1147559

Sampson, M. R., Frymoyer, A., Rattray, B., Cotten, C. M., Smith, P. B., Capparelli, E., et al. (2014). Predictive performance of a gentamicin population pharmacokinetic model in neonates receiving full-body hypothermia. Ther. Drug Monit. 36 (5), 584-589. doi:10.1097/FTD.0000000000000056

Schreuder, M. F., Bueters, R. R., Huigen, M. C., Russel, F. G., Masereeuw, R., and van den Heuvel, L. P. (2011). Effect of drugs on renal development. Clin. J. Am. Soc. Nephrol. 6 (1), 212-217. doi:10.2215/CJN.04740510

Seale, A. C., Obiero, C. W., and Berkley, J. A. (2015). Rational development of guidelines for management of neonatal sepsis in developing countries. Curr. Opin. Infect. Dis. 28 (3), 225-230. doi:10.1097/QCO.0000000000000163

Seaton, C., Ignas, J., Muchohi, S., Kokwaro, G., Maitland, K., and Thomson, A. H. (2007). Population pharmacokinetics of a single daily intramuscular dose of gentamicin in children with severe malnutrition. J. Antimicrob. Chemother. 59 (4), 681-689. doi:10.1093/jac/dkl561

Sherwin, C. M., Kostan, E., Broadbent, R. S., Medlicott, N. J., and Reith, D. M. (2009). Evaluation of the effect of intravenous volume expanders upon the volume of distribution of gentamicin in septic neonates. Biopharm Drug Dispos. 30 (5), 276-280. doi:10.1002/bdd.666

Simen-Kapeu, A., Seale, A. C., Wall, S., Nyange, C., Qazi, S. A., Moxon, S. G., et al. (2015). Treatment of neonatal infections: a multi-country analysis of health system bottlenecks and potential solutions. BMC Pregnancy Childbirth 15 (Suppl. 2), S6. doi:10.1186/1471-2393-15-S2-S6

Stockmann, C., Spigarelli, M. G., Campbell, S. C., Constance, J. E., Courter, J. D., Thorell, E. A., et al. (2014). Considerations in the pharmacologic treatment and prevention of neonatal sepsis. Paediatr Drugs. 16 (1), 67-81. doi:10.1007/s40272-013-0057-x

Sumper, A. L., and Holford, N. H. (2011). Predicting weight using postmenstrual age-neonates to adults. Paediatr. Anaesth. 21 (3), 309-315. doi:10.1111/j.14609592.2011.03534.x

Thingvoll, E. S., Guillet, R., Caserta, M., and Dicenzo, R. (2008). Observational trial of a 48-hour gentamicin dosing regimen derived from Monte Carlo simulations in infants born at less than 28 weeks' gestation. J. Pediatr. 153 (4), 530-534. doi:10.1016/j.jpeds.2008.04.060

Thomson, A. H., Kokwaro, G. O., Muchohi, S. N., English, M., Mohammed, S., and Edwards, G. (2003). Population pharmacokinetics of intramuscular gentamicin administered to young infants with suspected severe sepsis in Kenya. Br. J. Clin. Pharmacol. 56 (1), 25-31. doi:10.1046/j.1365-2125.2003.01819.x

Touw, D. J., Westerman, E. M., and Sprij, A. J. (2009). Therapeutic drug monitoring of aminoglycosides in neonates. Clin. Pharmacokinet. 48 (2), 71-88. doi:10.2165/00003088-200948020-00001
Tucker, J., and McGuire, W. (2004). Epidemiology of preterm birth. BMJ 329 (7467), 675-678. doi:10.1136/bmj.329.7467.675

UNICEFThe UN Inter-Agency Group for Child Mortality Estimation (2018). Levels and trends in child mortality estimates. New York, NY: UNICEF.

Valitalo, P. A., van den Anker, J. N., Allegaert, K., de Cock, R. F., de Hoog, M., Simons, S. H., et al. (2015). Novel model-based dosing guidelines for gentamicin and tobramycin in preterm and term neonates. J. Antimicrob. Chemother. 70 (7), 2074-2077. doi:10.1093/jac/dkv052

van Maarseveen, E. M., Sprij, A., and Touw, D. J. (2016). Extended-interval dosing of gentamicin aiming for a drug-free period in neonates: a prospective cohort study. Ther. Drug Monit. 38 (3), 402-406. doi:10.1097/FTD. 0000000000000283

Vanpée, M., Blennow, M., Linné, T., Herin, P., and Aperia, A. (1992). Renal function in very low birth weight infants: normal maturity reached during early childhood. J. Pediatr. 121 (5 Pt 1), 784-788. doi:10.1016/s0022-3476(05) 81916-x

Vinks, A. A., Emoto, C., and Fukuda, T. (2015). Modeling and simulation in pediatric drug therapy: application of pharmacometrics to define the right dose for children. Clin. Pharmacol. Ther. 98 (3), 298-308. doi:10.1002/cpt.169

Waters, D., Jawad, I., Ahmad, A., Lukšić, I., Nair, H., Zgaga, L., et al. (2011). Aetiology of community-acquired neonatal sepsis in low and middle income countries. J. Glob. Health 1 (2), 154-170.

Wiese, G. (1988). Treatment of neonatal sepsis with ceftriaxone/gentamicin and with azlocillin/gentamicin: a clinical comparison of efficacy and tolerability. Chemotherapy 34 (2), 158-163. doi:10.1159/000238564

World Health Organization (2015). Guideline: managing possible serious bacterial infection in young infants when referral is not feasible [Online]. Switzerland. Available at: http://apps.who.int/iris/bitstream/10665/181426/1/ 9789241509268_eng.pdf.(Accessed June 21, 2018).

Yu, C. Z., Myers, S. R., and Faldasz, J. D. (2020). Simulated comparison of a Bayesian clinical decision support system versus standard of care for achieving gentamicin pharmacokinetic targets in neonates. Pediatr. Infect. Dis. J. 39 (4), 313-317. doi:10.1097/inf.0000000000002592

Zaidi, A. K., Ganatra, H. A., Syed, S., Cousens, S., Lee, A. C., Black, R., et al. (2011). Effect of case management on neonatal mortality due to sepsis and pneumonia. BMC Publ. Health 11 (Suppl. 3), S13. doi:10.1186/14712458-11-S3-S13

Zaidi, A. K., Baqui, A. H., Qazi, S. A., Bahl, R., Saha, S., Ayede, A. I., et al. (2013a). Scientific rationale for study design of community-based simplified antibiotic therapy trials in newborns and young infants with clinically diagnosed severe infections or fast breathing in South Asia and subSaharan Africa. Pediatr. Infect. Dis. J. 32 (Suppl. 1), S7-S11. doi:10.1097/ INF.0b013e31829ff5fc

Zaidi, A. K., Tikmani, S. S., Sultana, S., Baloch, B., Kazi, M., Rehman, H., et al. (2013b). Simplified antibiotic regimens for the management of clinically diagnosed severe infections in newborns and young infants in first-level facilities in Karachi, Pakistan: study design for an outpatient randomized controlled equivalence trial. Pediatr. Infect. Dis. J. 32 (Suppl. 1), S19-S25. doi:10.1097/INF.0b013e31829ff7aa

Zakova, M., Pong, S., Trope, A., Atenafu, E. G., Papaioannou, V., Bitnun, S. A., et al. (2014). Dose derivation of once-daily dosing guidelines for gentamicin in critically ill pediatric patients. Ther. Drug Monit. 36 (3), 288-294. doi:10. 1097/FTD.0000000000000016

Conflict of Interest: The authors declare that the research was conducted in the absence of any commercial or financial relationships that could be construed as a potential conflict of interest.

Copyright $\odot 2021$ D’Agate, Musuamba, Jacqz-Aigrain and Della Pasqua. This is an open-access article distributed under the terms of the Creative Commons Attribution License (CC BY). The use, distribution or reproduction in other forums is permitted, provided the original author(s) and the copyright owner(s) are credited and that the original publication in this journal is cited, in accordance with accepted academic practice. No use, distribution or reproduction is permitted which does not comply with these terms. 